\title{
Is There a Role for ERAS Program Implementation to Restart Bariatric Surgery After the Peak of COVID-19 Pandemic?
}

\author{
Giovanni Fantola ${ }^{1} \cdot$ Carlo Nagliati $^{2}$ (D) $\cdot$ Mirto Foletto $^{3} \cdot$ Alessandro Balani $^{2} \cdot$ Roberto Moroni $^{1}$ \\ Published online: 15 May 2020 \\ (C) Springer Science+Business Media, LLC, part of Springer Nature 2020
}

The ongoing pandemic from coronavirus disease 2019 (COVID-19) has suddenly and deeply changed the daily practice in surgical departments all around the world [1].

Several surgical societies hurriedly prepared recommendations [2-6], the need to reduce, postpone, or cancel all elective surgical cases or endoscopic invasive procedures being the common shared starting point.

A negative prognostic link of obesity as a risk factor for a severe disease in case of SARS-COV-2 infection has already been suggested $[7,8]$, and further studies seem to confirm an elevated body mass index (BMI) as the first preventable risk factor $[9,10]$, just following advanced age. A BMI $>35 \mathrm{~kg} / \mathrm{m}^{2}$ would increase about seven times the risk of switching to mechanical ventilation compared to BMI $<25 \mathrm{~kg} / \mathrm{m}^{2}$ [9].

In Italy, accordingly to other affected countries, bariatric surgery (BS) was promptly and diffusely stopped. The International Federation for the Surgery of Obesity and Metabolic Disorders (IFSO) gave us a general recommandation [11]:

"All elective surgical and endoscopic cases for metabolic and bariatric surgery should be postponed during the pandemic. This minimises risks to both patient and healthcare team, as well as reducing the utilisation of unnecessary resources, such as beds, ventilators and personal protective equipment. In addition, postponing these services will minimise potential exposure of the COVID-19 virus to unsuspecting healthcare providers and patients".

Giovanni Fantola and Carlo Nagliati contributed equally to this work.

Carlo Nagliati

carlonagliati@yahoo.it

1 Department of Surgery, Obesity Surgery Unit, A.O.B. Brotzu, Cagliari, Italy

2 Department of Surgery, San Giovanni di Dio Hospital, Gorizia, Italy

3 Week Surgery, Bariatric Unit, University of Padova, Padua, Italy
Obesity represents an epidemic public health issue [12-14]. Sixteen million people with obesity are living in Italy and 15,000 of them underwent BS in 2019 [15], that represents the most effective treatment at the moment [12].

COVID-19 pandemic showed the intrinsic frailty of those patients affected by obesity and metabolic syndrome, while obesity "per se" is considered a risk factor for infection, need ICU admission, and death [16, 17].

Therefore, we could speculate that it should be mandatory to treat obesity as best and early as we can in order to contribute fighting the COVID-19 pandemic.

We still do not know what will happen after COVID19 peak, but it is reasonable to envision a slow and progressive restart of elective surgical activity during the second pandemic phase, when the risk of infection could remain still quite high but acceptable.

In order to properly manage this resumption, every bariatric surgeon should ask her/himself two questions: when and how am I supposed to restart? Should I select my first patients?

All bariatric surgeons might have experienced the loss of some severely ill patients before surgery, passing away or developing more critical illness just due to the waiting list. How many of them are we loosing now in the COVID-19 era?

It is difficult to answer all these questions. Hospital will remain one of the main sites of virus spreading, and surgeons need to protect patient with obesity from the present COVID19 extraordinary virulence. On the other hand, BS could prospectively save lives, given the poor prognosis of COVID-19 in patients with obesity and metabolic syndrome. In this setting, it might be important to select patients and to identify safe pathways for surgical management.

Is it possible to achieve a full COVID-free hospital? Maybe in the future, but not now. Is it possible to achieve a COVIDfree patient and health-care staff? Hopefully, but now we are still dealing with virus diagnostic inaccuracies.

We need safe and low-infection risk pathways of care in our hospitals. Some help could come from the extensive use of 
ERAS protocols in bariatric surgery, which has been conceived to reduce length of hospital stay and to promote early functional recovery [18-23]. Reducing hospitalization can reduce infection risk. Moreover, ERAS protocol is considered a safe and standardized pathway to regain an early risk-free return at home after operation.

Furthermore, most of the Italian hospitals and the healthcare facilities are probably unable to undergo to a proper reorganization, mostly due to the fact that the COVID-19 pandemic is diverting and requiring most of our human and structural resources. Therefore, the rationalization of the resources and the efficiency of surgical pathway may represent the possible way out of this funnel, as several studies [21, 22] showed that ERAS could improve all logistics aspects along with an overall positive impact on outcomes.

Finally, ERAS protocol could be a major turning point for this second pandemic phase, capable to reduce intra-hospital infection rates and to promote better resource allocation, significantly improving the performances of BS centers.

Acknowledgments The authors thank Marina Troian for revising the final English version of this letter.

\section{Compliance with Ethical Standards}

Conflict of Interest The authors declare that they have no conflicts of interest.

Ethical Approval Statement This article does not contain any studies with human participants or animals performed by any of the authors.

Informed Consent Informed consent does not apply.

\section{References}

1. Brindle M, Gawande A. Managing COVID-19 in surgical systems. Ann Surg. 2020:1. https://doi.org/10.1097/SLA. 0000000000003923.

2. Coccolini F, Perrone G, Chiarugi M, et al. Surgery in COVID-19 patients: operational directives. World J Emerg Surg. 2020;15(1): 25. https://doi.org/10.1186/s13017-020-00307-2.

3. Royal College of Surgeons in Ireland. Updated Intercollegiate General Surgery Guidance on COVID-19. Tuesday 7 April 2020. https://www.rcseng.ac.uk/coronavirus/joint-guidance-forsurgeons-v2/

4. Associazione Chirurghi Ospedalieri Italiani - Società Italiana di Chirurgia. ACOI_SIC COVID-19. Society Statement. March 30, 2020. https://www.sicitalia.org/wp-content/uploads/2020/04/ 20200330_Covid-19-Acoi_Sic.pdf

5. American College of Surgeons. COVID-19: recommendations for management of elective surgical procedures. Online March 13,
2020. https://www.facs.org/covid-19/clinical-guidance/electivesurgery

6. Pryor A. SAGES and EAES recommendations regarding surgical response to Covid-19 crisis. March 29, 2020. https://www.sages. org/recommendations-surgical-response-covid-19/

7. Rebelos E, Moriconi D, Virdis A, et al. Importance of metabolic health in the era of COVID-19. Metabolism. 2020;108:154247. https://doi.org/10.1016/j.metabol.2020.154247.

8. Stefan N, Birkenfeld A, Schulze MB, et al. Obesity and impaired metabolic health in patients with COVID-19. Nat Rev Endocrinol. 2020; https://doi.org/10.1038/s41574-020-0364-6.

9. Simonnet A, Chetboun M, Poissy J, et al. High prevalence of obesity in severe acute respiratory syndrome coronavirus-2 (SARS$\mathrm{CoV}-2$ ) requiring invasive mechanical ventilation. Obesity (Silver Spring). 2020; https://doi.org/10.1002/oby.22831.

10. Caussy C, Wallet F, Laville M, et al. Obesity is associated with severe forms of COVID-19. Obesity (Silver Spring). 2020; https://doi.org/10.1002/oby.22842.

11. Yang W, Wang C, Shikora S, Know L. Recommendations for metabolic and bariatric surgery during the COVID-19 pandemic from IFSO. Obes Surg 14 April 2020.

12. Schauer PR, Bhatt DL, Kirwan JP, et al. Bariatric surgery versus intensive medical therapy for diabetes - 5-year outcomes. N Engl J Med. 2017;376(7):641-51.

13. Angrisani L, Santonicola A, Iovino P, et al. IFSO worldwide survey 2016: primary, endoluminal, and revisional procedures. Obes Surg. 2018;28(12):3783-94.

14. Busetto L, Dicker D, Azran C, et al. Practical recommendations of the obesity management task force of the European Association for the Study of obesity for the post-bariatric surgery medical management. Obes Facts. 2017;10(6):597-632.

15. Registro nazionale SICOB[Internet]. Available at: https://www. sicob.org/area_04_medici

16. Huang JF, Wang XB, Zheng KI, et al. Obesity hypoventilation syndrome and severe COVID-19. Metabolism. 2020;22:154249. https://doi.org/10.1016/j.metabol.2020.154249.

17. Dietz W, Santos-Burgoa C. Obesity and its implications for COVID-19 mortality. Obesity (Silver Spring). 2020;

18. Nagliati C, Troian M, Pennisi D, et al. Enhanced recovery after bariatric surgery: 202 consecutive patients in an Italian bariatric center. Obes Surg. 2019;29(10):3133-41.

19. Trotta M, Ferrari C, D’Alessandro G, et al. Enhanced recovery after bariatric surgery (ERABS) in a high-volume bariatric center. Surg Obes Relat Dis Off J Am Soc Bariatr Surg ottobre. 2019;15(10): 1785-92.

20. Małczak P, Pisarska M, Piotr M, et al. Enhanced recovery after bariatric surgery: systematic review and meta-analysis. Obes Surg. 2017;27(1):226-35.

21. Mannaerts GHH, van Mil SR, Stepaniak PS, et al. Results of implementing an enhanced recovery after bariatric surgery (ERABS) protocol. Obes Surg febbraio. 2016;26(2):303-12.

22. Goretti G, Marinari GM, Vanni E, et al. Value-based healthcare and enhanced recovery after surgery implementation in a high-volume bariatric center in Italy. Obes Surg. 24 febbraio 2020.

23. Carron M, Safaee Fakhr B, Ieppariello G, et al. Perioperative care of the obese patient. Br J Surg. 2020;107(2):e39-55.

Publisher's Note Springer Nature remains neutral with regard to jurisdictional claims in published maps and institutional affiliations. 